\title{
Extrusão de misturas de castanha do Brasil com mandioca
}

\author{
Extrusion of Brazil nut and cassava flour mixtures
}

Maria Luzenira de SOUZA ${ }^{1 *}$, Hilary Castle de MENEZES ${ }^{2}$

\begin{abstract}
Resumo
Considerando-se que a castanha do Brasil apresenta elevado potencial nutritivo, baixo consumo no Brasil, baixo valor agregado e é um produto orgânico, além da alta produtividade, do baixo custo da mandioca e da tecnologia de extrusão termoplástica apresentarem ampla aplicabilidade e vantagens, este trabalho teve como objetivo empregar estas três variáveis, para formular misturas com castanha do Brasil e farinha de mandioca e processá-las por extrusão, visando à obtenção de produtos extrusados ricos em proteína vegetal e prontos para o consumo. Foram utilizadas torta de amêndoa de castanha do Brasil semidesengordurada e farinha de mandioca para formulações das misturas para extrusão. Aplicou-se o delineamento fatorial completo composto central $\left(2^{3}\right)$, com 3 variáveis independentes e a metodologia de superfície de resposta foi usada para avaliar os resultados da composição centesimal e o valor calórico, frente às variações de castanha, umidade e temperatura. Os resultados indicam que as formulações com maiores quantidades de castanha apresentam quantidades de proteínas, lipídios e cinzas mais elevadas, já as formulações com menores teores de castanha apresentam maiores percentuais de carboidratos. Os coeficientes de regressão médios do modelo estatístico para as respostas são: umidade 7,40; carboidratos 51,09; proteínas 15,34; lipídios 11,77; fibra total 9,92 e kcal 371,65. Os ensaios com menores teores de castanha e maiores de farinha apresentam-se mais expandidos e de cor clara, enquanto que aqueles com maiores teores de castanha não se expandem e têm a cor acinzentada. Conclui-se que a adição de castanha semidesengordurada à farinha de mandioca pode ser submetida à extrusão, originando um produto extrusado fonte de proteína vegetal, pronto para o consumo e que pode atender à exigência de consumidores que não utilizam proteínas de origem animal.

Palavras-chave: castanha do Brasil desengordurada; extrusão termoplástica; composição centesimal; metodologia de superfície de resposta.
\end{abstract}

\begin{abstract}
Considering that Brazil nut presents high nutritional potential, low consumption in Brazil, low added-value and is an organic product; that cassava has high productivity and low cost; and that the technology of thermoplastic extrusion presents wide applicability and considerable advantages, the objective of this work was to use these three variables, formulating Brazil nut and cassava flour mixtures and processing them by extrusion, with the aim of obtaining ready-to-eat extruded products containing high levels of vegetable protein. Semi-defatted Brazil nut cake and cassava flour were used to formulate the mixtures for extrusion. A complete factorial central composite design $\left(2^{3}\right)$ with 3 independent variables, and the response surface methodology were used to evaluate the results of the proximate composition and caloric value, according to the variations in the quantity of nut, moisture content and temperature. The results indicate that the mixtures with higher Brazil nut levels present higher levels of protein, fat and ash, while the mixtures with less Brazil nut present higher levels of carbohydrate. The average regression coefficients of the statistical model for the responses are: moisture 7.40; carbohydrate 51.09; protein 15.34; fat 11.77; total fibre 9.92 and kcal 371.65. The trials with lower quantities of Brazil nut and higher quantities of flour are more expanded and of a lighter colour, while those with more Brazil nut do not expand and are greyish in colour. It is concluded that the addition of Brazil nut to cassava flour results in a mixture that could be submitted to extrusion, producing an extruded product that could serve as a ready-to-eat source of vegetable protein, and attend the demands of consumers who do not consume proteins of animal origin.
\end{abstract}

Keywords: Brazil nut; thermoplastic extrusion; proximate composition; response surface methodology.

\section{Introdução}

A castanha do Brasil (Bertholletia excelsa, H. B. K.), também conhecida como castanha-do-pará, é um dos principais produtos da biodiversidade da Floresta Amazônica. Têm alto potencial econômico, especialmente na Amazônia brasileira, na qual representa um dos elementos principais para a economia das famílias extrativistas.

Apesar dos avanços tecnológicos verificados, a exploração da castanha do Brasil ainda é exclusivamente extrativista, embora hoje já se observe interferência do Ministério da Agricultura,
Pecuária e Abastecimento para incentivar estudos em práticas de produção e pós-colheita que garantam a qualidade e o mercado, devido às exigências sanitárias cada vez mais rígidas por parte do mercado internacional.

A castanha do Brasil contém uma amêndoa com elevado teor de proteínas de alto valor biológico, lipídios, fibras (PACHECO; SCUSSEL, 2006; SOUZA, 2003), vitamina E e, em ordem decrescente, minerais como fósforo, potássio, magnésio, cálcio e selênio (CHUNHIENG et al., 2004; SOUZA;

Recebido para publicação em 5/5/2007

Aceito para publicação em 15/10/2007 (002506)

Departamento de Ciências Agrárias, Universidade Federal do Acre - UFAC, Campus Universitário, Estrada Dias Martins, BR 364, Km 4, CEP 69915-900, Rio Branco - AC, Brasil,E-mail:mluzen@hotmail.com

Departamento de Tecnologia de Alimentos, Faculdade de Engenharia de Alimentos, Universidade Estadual de Campinas - UNICAMP, CP 6121, E-mail: hilary@mpc.com.br

${ }^{*}$ A quem a correspondência deve ser enviada 
MENEZES, 2004). Este último é um oligo elemento presente em maior quantidade na castanha do Brasil dentre todos os alimentos conhecidos.

A castanha do Brasil tem pesquisa focada na presença de selênio, devido à ação antioxidante nos processos metabólicos (PACHECO; SCUSSEL, 2006). A atuação do selênio está relacionada com a enzima glutationa-peroxidase, dependente do Se, no que se refere à formação de radicais livres no organismo (HOLBEN; SMITH, 1999), proteção contra a ação nociva de metais pesados, prevenção de doenças crônicas não transmissíveis e aumento da resistência do sistema imunológico (COZZOLINO, 2001; GONZAGA, 2002).

Por outro lado Souza (2003) e Souza e Menezes (2004) destacam que além do selênio, outro apelo muito forte para a utilização da castanha do Brasil é a quantidade e a qualidade da proteína contida na amêndoa e o baixo emprego no mercado interno pelas indústrias processadoras de alimentos.

A mandioca (Manihot esculenta, Crantz) é uma espécie de grande importância agronômica, classificada como doce ou amarga. É adaptada às condições edafo-climáticas brasileiras, tolerante a estresses bióticos e abióticos, podendo apresentar rendimentos elevados até mesmo em solos já esgotados por outras culturas (GRIZOTTO, 2001). É uma importante fonte de amido para a indústria de alimentos, com uma produção mundial de raízes estimada em mais de um trilhão de toneladas ao ano, considerada um produto agrícola de alta relevância para os países de clima tropical (SOARES JÚNIOR, 1995).

Amplamente consumida na região Amazônica e no Nordeste brasileiro, apresenta muitas utilizações; seja in natura pronta para o uso, cozida, frita ou congelada em pedaços, em farinha, polvilhos doce e azedo, fécula, mingau, tapioca, ingrediente para bolos, biscoitos, pães, massas, salgados, tucupi, amido nativo e modificado, indústrias de papéis, indústrias têxteis, alimentação animal e outros.

A extrusão termoplástica é um processo tecnológico, no qual o atrito mecânico é combinado com o calor para, continuamente, misturar, plasticizar e gelatinizar amido, desnaturar materiais protéicos e inativar enzimas, reestruturando-os para criar novas formas (EL-DASH, 1987; ICTA, 2006).

De acordo com Camire, Camire e Krumhar (1990), Yaylayan, Fichtali e Van de Voort (1992), Gutkoski (1997), Ainsworth et al. (1999), Alonso, Aguirre e Marzo (2000) e ICTA (2006), a extrusão termoplástica é um processo de alta temperatura e curto tempo (HTST-high temperature short time), com período de residência no extrusor de 1 a 2 minutos em média, que minimiza a degradação de nutrientes, melhora a digestibilidade de proteínas, elimina fatores antinutricionais e enzimas e, em alguns casos, reduz a rancidez oxidativa devido ao poder antioxidante de alguns intermediários da reação de Maillard.

Chen et al. (1991) complementam que a extrusão é um processo contínuo de um reator que trabalha a altas temperaturas e curto espaço de tempo, em combinação com a força de cisalhamento e percentuais de umidade relativamente baixos, adequados para transformar várias matérias-primas em produtos intermediários ou finais, totalmente modificados.
A tecnologia permite maior facilidade na produção de misturas alimentícias destinadas ao consumo humano, produzindo uma variedade de produtos, tais como: alimentos infantis, proteínas vegetais texturizadas, bebidas em pó instantâneas, amidos modificados para uso industrial, rações pré-cozidas para animais, refeições rápidas, cereais pré-cozidos, snacks e outros produtos diversos (EL-DASH, 1987; UFRGS, 2006). É bastante empregada na produção de cereais matinais e produtos expandidos, texturizados, farinhas instantâneas e amidos prégelatinizados utilizados na formulação de sopas de preparo rápido, molhos semiprocessados, produtos de confeitaria e outros (EL-DASH, 1982).

Neste contexto, levando em conta que a castanha do Brasil apresenta importante potencial nutritivo, baixa utilização no Brasil como ingrediente na elaboração de alimentos e/ou consumo in natura, baixa agregação de valor (a maior parte da produção, cerca de $90 \%$, é exportada desidratada com casca para outros países, onde gera emprego, renda e agrega valor, devido ao amplo uso como ingrediente de vários produtos industrializados, e é um produto orgânico; a mandioca tem alta produtividade e baixo preço, e aplicabilidade e vantagens da extrusão termoplástica, sendo assim, este trabalho teve como objetivo formular misturas a partir de castanha do Brasil com mandioca e processar por extrusão termoplástica, visando a obtenção de um produto extrusado rico em proteína pronto para o consumo.

\section{Material e métodos}

\subsection{Matéria-prima}

Foram utilizadas torta de amêndoa de castanha do Brasil semidesengordurada por prensagem e farinha de mandioca nas formulações das misturas dos ensaios.

\subsection{Preparo dos ensaios e delineamento experimental}

\section{Formulação de misturas de torta de amêndoa de castanha do Brasil com farinha de mandioca}

Para elaboração das formulações dos ensaios foi utilizado o delineamento fatorial completo composto central $\left(2^{3}\right)$, contendo 3 variáveis independentes, 4 repetições no ponto central e 6 pontos axiais, totalizando 18 experimentos, segundo metodologia descrita por Barros Neto, Scarminio e Bruns (1995).

As variáveis independentes estudadas foram: porcentagem de torta de amêndoa de castanha, umidade e temperatura, estabelecidas em níveis codificados: $-\alpha,-1,0,+1,+\alpha$. O valor de $\alpha$ foi em função do número de variáveis independentes $(n=3)$, sendo definido pela equação: $\alpha=\left(2^{n}\right)^{1 / 4}=\left(2^{3}\right)^{1 / 4}=1,68$. As faixas de variação entre os limites inferior e superior de cada variável independente foram estabelecidas a partir de dados da literatura e de testes preliminares realizados, utilizando os respectivos valores reais, conforme a Tabela 1, para aplicação da metodologia de superfície de resposta, de acordo com Barros Neto, Scarminio e Bruns (1995). 
Para modelar cada ensaio (tratamento), pesou-se as matérias-primas separadamente, de acordo com o delineamento experimental apresentado na Tabela 2, utilizando-se para cada um a porcentagem de farinha de mandioca necessária para completar $100 \%$ em cada um dos 18 ensaios. Todos foram condicionados com água destilada, suficiente para atingir o nível de umidade desejado. O volume de água foi calculado, após determinação da umidade inicial das misturas, em balança digital de determinação de umidade por infravermelho, modelo $\mathrm{AD}-4714$, aplicando-se os resultados na Equação 1:

Volume de água a adicionar $=\left(\mathrm{U}_{\mathrm{f}}-\mathrm{U}_{\mathrm{i}}\right) /\left(100-\mathrm{U}_{\mathrm{f}}\right) \times \mathrm{pa}$

em que: $U_{\mathrm{f}}=$ umidade final; $\mathrm{U}_{\mathrm{i}}=$ umidade inicial; $\mathrm{pa}=$ peso em gramas da amostra.

A homogeneização no condicionamento das misturas foi realizada em batedeira elétrica KITCHENAID, modelo K 45SS, em constante agitação por 15 minutos, enquanto a água era adicionada, gota a gota, com auxílio de uma bureta. Cada ensaio

Tabela 1. Níveis codificados e reais das variáveis independentes estudadas nas formulações das misturas e no processo de extrusão.

\begin{tabular}{lrrrrr}
\hline \multirow{2}{*}{$\begin{array}{c}\text { Variáveis } \\
\text { independentes }\end{array}$} & \multicolumn{5}{c}{ Níveis codificados e reais das variáveis } \\
& \multicolumn{1}{c}{$-\alpha$} & -1 & 0 & +1 & $+\alpha$ \\
\hline $\mathrm{x}_{1}$ (castanha \%) & 19,80 & 30 & 45 & 60 & 70,2 \\
$\mathrm{x}_{2}$ (umidade \%) & 14,20 & 17 & 21 & 25 & 27,7 \\
$\mathrm{x}_{3}$ (temperatura $\left.{ }^{\circ} \mathrm{C}\right)$ & 116,40 & 130 & 150 & 170 & 183,6 \\
\hline
\end{tabular}

Valores codificados: $\pm \alpha ; 0 ; \pm 1$; pontos axiais ou estrela $\pm \alpha= \pm 1,68$; ponto central $\mathrm{C}=0$; e pontos máximos e mínimos $= \pm 1$.

Tabela 2. Delineamento fatorial completo composto central $\left(2^{3}\right)$, com 3 variáveis independentes, 4 repetições no ponto central (C) e 6 pontos axiais.

\begin{tabular}{|c|c|c|c|}
\hline \multirow[t]{2}{*}{$\begin{array}{l}\text { Número de } \\
\text { experimento }\end{array}$} & \multicolumn{3}{|c|}{$\begin{array}{c}\text { Níveis das variáveis } \\
\text { independentes codificadas }\end{array}$} \\
\hline & $\begin{array}{c}\mathrm{x}_{1}(\%) \\
\text { Castanha }\end{array}$ & $\begin{array}{c}\mathrm{x}_{2}(\%) \\
\text { Umidade }\end{array}$ & $\begin{array}{c}\mathrm{x}_{3}\left({ }^{\circ} \mathrm{C}\right) \\
\text { Temperatura }\end{array}$ \\
\hline 01 & $-1(30)$ & $-1(17)$ & $-1(130)$ \\
\hline 02 & $+1(60)$ & $-1(17)$ & $-1(130)$ \\
\hline 03 & $-1(30)$ & $+1(25)$ & $-1(130)$ \\
\hline 04 & $+1(60)$ & $+1(25)$ & $-1(130)$ \\
\hline 05 & $-1(30)$ & $-1(17)$ & $+1(170)$ \\
\hline 06 & $+1(60)$ & $-1(17)$ & $+1(170)$ \\
\hline 07 & $-1(30)$ & $+1(25)$ & $+1(170)$ \\
\hline 08 & $+1(60)$ & $+1(25)$ & $+1(170)$ \\
\hline 09 & $0(45)$ & $0(21)$ & $-\alpha 1,68(116,4)$ \\
\hline 10 & $0(45)$ & $0(21)$ & $+\alpha 1,68(183,6)$ \\
\hline 11 & $0(45)$ & $-\alpha 1,68(14,28)$ & $0(150)$ \\
\hline 12 & $0(45)$ & $+\alpha 1,68(27,72)$ & $0(150)$ \\
\hline 13 & $-\alpha 1,68(19,8)$ & $0(21)$ & $0(150)$ \\
\hline 14 & $+\alpha 1,68(70,2)$ & $0(21)$ & $0(150)$ \\
\hline $15(\mathrm{C})$ & $0(45)$ & $0(21)$ & $0(150)$ \\
\hline $16(\mathrm{C})$ & $0(45)$ & $0(21)$ & $0(150)$ \\
\hline $17(\mathrm{C})$ & $0(45)$ & $0(21)$ & $0(150)$ \\
\hline $18(\mathrm{C})$ & $0(45)$ & $0(21)$ & $0(150)$ \\
\hline
\end{tabular}

$\mathrm{C}$ (ponto central). condicionado foi embalado em sacos de polietileno, selado e armazenado sob refrigeração a $5{ }^{\circ} \mathrm{C}$ por 24 horas por proporcionar a distribuição e absorção mais uniforme da umidade para posterior extrusão.

\section{Processamento por extrusão das misturas formuladas}

A extrusão dos 18 ensaios foi efetuada em extrusor Brabender de rosca única, $380 \mathrm{~mm}$ de comprimento por $19 \mathrm{~mm}$ de diâmetro e taxa de compressão 3:1, matriz cilíndrica de $2 \mathrm{~mm}$ de diâmetro, no Laboratório de Cereais da Faculdade de Engenharia de Alimentos da Universidade Estadual de Campinas, conforme processo descrito no Fluxograma da Figura 1.

O processamento foi iniciado quando as três diferentes zonas do extrusor atingiram as temperaturas definidas no

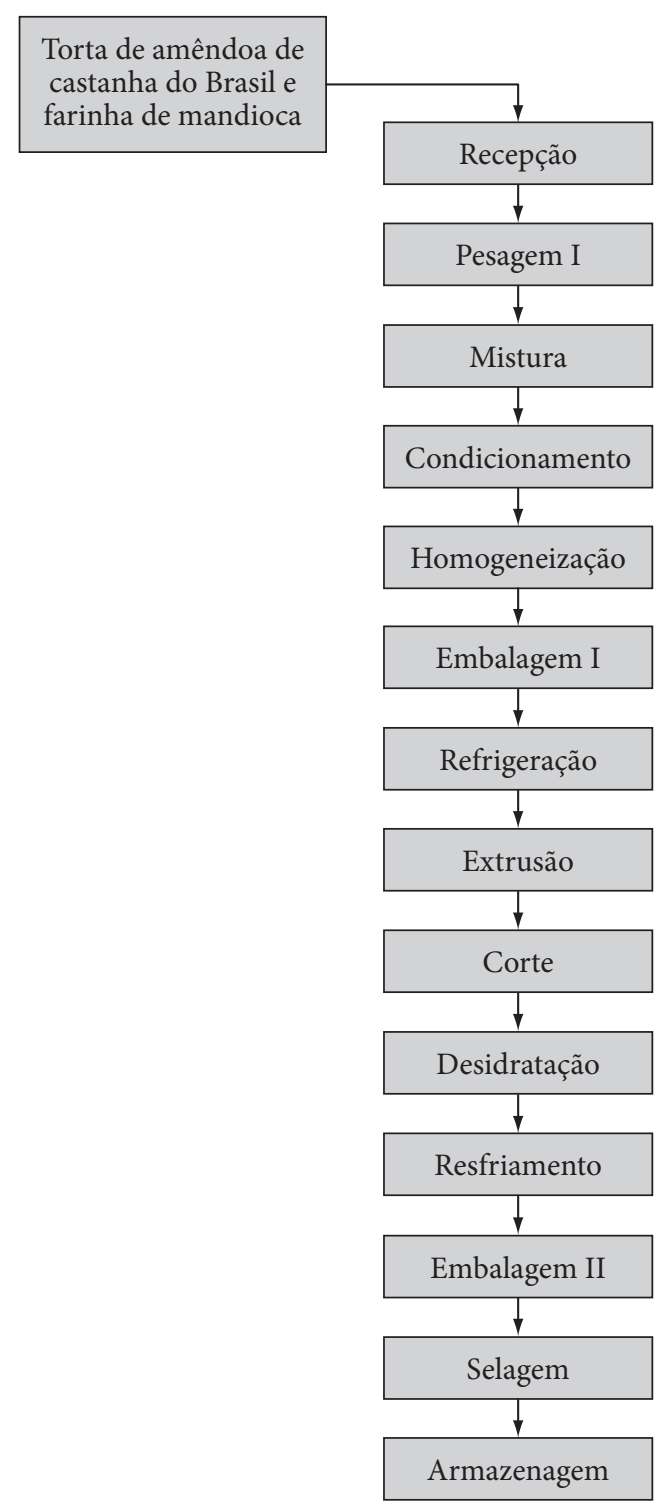

Figura 1. Fluxograma do processamento por extrusão de misturas formuladas com torta de amêndoa de castanha do Brasil e farinha de mandioca. 
planejamento, mantendo-se constantes as temperaturas da $1^{\text {a }}$ Zona $=100{ }^{\circ} \mathrm{C}$ e da $2^{\text {a }}$ Zona $=110^{\circ} \mathrm{C}$; enquanto as temperaturas utilizadas nas $3^{\text {as }}$ Zonas foram aquelas designadas para cada tratamento, de acordo com o planejamento experimental (Tabela 2), mantendo-se a taxa de alimentação das misturas constante a $4,8 \mathrm{~kg} / \mathrm{h}$ a $175 \mathrm{rpm}$ (SOUZA, 2003).

Depois que o processo atingiu o equilíbrio visual na leitura do torque do extrusor, o material extrusado foi coletado manualmente, cortado em pedaços de cerca de $3 \mathrm{~cm}$, distribuído em bandejas, desidratado em estufa com circulação de ar a $60{ }^{\circ} \mathrm{C}$ por 48 horas (ARTZ; WARREN; VILLOTA, 1990), resfriado à temperatura ambiente, pesado, embalado em sacos flexíveis aluminizados multicamadas com selagem térmica e armazenado em local seco e fresco até a realização das análises.

\section{Análise da composição centesimal e valor energético}

Cada uma das 18 formulações extrusadas foi moída em moinho de rolos e tamisada em US Standard malha 60 mesh para realização das análises físico-químicas de umidade, lipídios, cinzas, fibras totais e proteínas (método micro-Kjeldhal \%N x 5,46), seguindo os procedimentos da AACC (1995). Os resultados de carboidratos foram estimados por diferença (subtraindo-se de 100 o somatório de proteínas, lipídios, cinzas e umidade) e os de energia metabolizável em kcal, a partir dos percentuais dos resultados dos nutrientes energéticos, aplicando os fatores de conversão de Atwater de $4 \mathrm{kcal}$ por grama para carboidratos e proteínas e $9 \mathrm{kcal}$ por grama para lipídios, respectivamente, conforme Anderson et al. (1988). Todas as análises foram realizadas em duplicata.

\section{Análise estatística}

Para as análises estatísticas dos resultados utilizou-se o planejamento fatorial completo $2^{3}$, utilizando-se a metodologia multivariável para avaliar o efeito das variáveis de estudo em relação às respostas, bem como suas interações (BARROS NETO; SCARMINIO; BRUNS, 1995). A Tabela 1 apresenta os valores dos níveis usados no planejamento experimental.

As médias das respostas experimentais foram tratadas através de análises de regressão múltipla, para desenvolver modelos matemáticos de segunda ordem, contendo parâmetros lineares, quadráticos e de interação das três variáveis independentes, utilizando o Programa Statistic for Windows versão 5.0 (1995).

A Equação 2 geral do modelo estatístico preditivo foi representada por um polinômio de segunda ordem e descrita a seguir:

$Y_{i}=\beta_{\tilde{0}}+\beta_{1} X_{1}+\beta_{2} X_{2}+\beta_{3} X_{3}+\beta_{11} X_{1}^{2}+\beta_{22} X_{2}^{2}+$

$\beta_{33} X_{3}^{2}+\beta_{12} X_{1} X_{2}+\beta_{13} X_{1} X_{3}+\beta_{23} X_{2} X_{3}+\varepsilon$

em que:

$\mathrm{Y}_{\mathrm{i}}=$ Função resposta ou variável dependente;

$\mathrm{X}_{1}, \mathrm{X}_{2} \mathrm{X}_{3}=$ Níveis codificados das variáveis independentes, sendo: $\mathrm{X}_{1}$ - Castanha (\%); $\mathrm{X}_{2}$ - Umidade (\%) e $\mathrm{X}_{3}$ - Temperatura de extrusão $\left({ }^{\circ} \mathrm{C}\right)$. $\beta_{\tilde{0}}=$ Média ou ponto central do sistema. É encontrado pela diferença parcial da equação de regressão em relação a cada variável independente e resolvendo o sistema de equações lineares simultaneamente.

$\beta_{1}, \beta_{2}$ e $\beta_{3}=$ Coeficientes lineares das variáveis independentes.

$\beta_{11}, \beta_{22}$ e $\beta_{33}=$ Coeficientes dos termos quadrados das variáveis independentes.

$\beta_{12}, \beta_{13}$ e $\beta_{23}=$ Coeficientes dos termos de interação entre as variáveis independentes.

$\varepsilon=$ Resíduo que mede o erro experimental do modelo apresentando uma distribuição normal com média zero e variância igual a $\mathrm{s}^{2}$.

Na construção do modelo, eliminou-se o termo não significativo da tabela de coeficientes de regressão para se obter um modelo final ajustado capaz de descrever as características da região analisada.

Foram construídos gráficos de superfícies de respostas e de contorno com o emprego do programa Statistic for Windows versão 5,0 (1995) para determinar o efeito das variáveis independentes sobre as respostas observadas, fixando-se um dos fatores ou variáveis independentes em um dos níveis zero, + 1 e -1 , verificando assim suas influências sobre as respostas.

\section{Resultados e discussão}

\subsection{Efeitos das variáveis de extrusão na composição centesimal e valor energético dos produtos extrusados}

$\mathrm{Na}$ Tabela 3 estão apresentados os resultados obtidos (base seca) em percentuais dos produtos extrusados, referentes à umidade, carboidratos, proteínas, lipídios, cinzas, fibras totais e calorias. Verificou-se que os ensaios com maiores teores de castanha apresentaram percentuais mais elevados de proteínas, lipídios, fibras e cinzas, e quanto menor o percentual de castanha mais elevado o percentual de carboidratos. Tais resultados eram esperados, uma vez que a finalidade de adicionar castanha à farinha de mandioca nas formulações foi de enriquecer a mistura, especialmente em proteína, para obtenção de um produto extrusado fonte de proteína de origem vegetal, pronto para o consumo, que atendesse à reivindicação de consumidores que não utilizam proteínas de origem animal, mas necessitam de produtos alternativos prontos para o consumo imediato, ricos em proteínas de origem vegetal, carboidratos e fibras e que possam suprir as deficiências protéicas.

Observou-se também que as formulações (ensaios) com menores percentuais de castanha e maiores de farinha apresentaram-se mais expandidas e de coloração mais clara. Os ensaios que continham maiores teores de castanha não se expandiram e tinham a coloração acinzentada, o que pode ser justificado pela maior quantidade de proteína e película marrom de castanha.

Estas descobertas corroboram com os achados de Harper (1981), ao enfatizar que a adição de ingredientes com alto teor de proteína tende a reduzir a expansão de uma mistura extrusada. Formulação contendo alta quantidade de proteína resulta em 
uma massa mais viscosa, necessitando de maior energia mecânica durante o processo e maior pressão na matriz. Chang et al. (2001), trabalhando com extrusão de amido de mandioca em mistura com isolado protéico de soja, também observaram que níveis de isolado protéico de soja maiores que $25 \%$ reduziram a expansão dos extrusados.

Aplicando-se a metodologia de superfície de resposta (BARROS NETO; SCARMINIO; BRUNS, 1995) aos resultados da Tabela 3, obteve-se os coeficientes de regressão e os parâmetros do modelo estatístico das variáveis dependentes (respostas) que foram ajustados, após exclusão dos valores não significativos, para descrever os modelos, conforme apresentado na Tabela 4.

Na Tabela 4 observou-se, em relação ao percentual de umidade dos produtos extrusados, que apenas as variáveis independentes, temperatura (L) e castanha (L) foram significativas a $95 \%$ de probabilidade.

O sinal positivo do parâmetro linear da variável temperatura indica que o aumento dessa variável, dentro da faixa de temperatura estudada, contribuiu para o aumento do teor de umidade. O valor negativo para o parâmetro castanha linear significa que elevando o percentual de castanha, o teor de umidade diminui.

Tabela 3. Resultados da composição centesimal e do valor calórico de produtos de castanha do Brasil com farinha de mandioca extrusados.

\begin{tabular}{|c|c|c|c|c|c|c|c|c|c|c|}
\hline \multirow[t]{2}{*}{$\begin{array}{c}\text { Formulação } \\
\text { (Ensaio) }\end{array}$} & \multicolumn{3}{|c|}{$\begin{array}{c}\text { Variáveis } \\
\text { independentes }\end{array}$} & \multicolumn{7}{|c|}{ Respostas $\left({ }^{\star}\right)$} \\
\hline & $\mathrm{x}_{1}$ & $\mathrm{x}_{2}$ & $\mathrm{x}_{3}$ & Umidade (\%) & Carboidrato (\%) & Proteína (\%) & Lipídio (\%) & Cinza (\%) & Fibra (\%) & kcal.100 g ${ }^{-1}$ \\
\hline 01 & -1 & -1 & -1 & 6,6 & 66,91 & 11,54 & 5,31 & 3,27 & 6,37 & 361,59 \\
\hline 02 & 1 & -1 & -1 & 6,20 & 43,93 & 21,53 & 9,62 & 5,85 & 12,87 & 348,42 \\
\hline 03 & -1 & 1 & -1 & 6,45 & 62,48 & 12,35 & 8,66 & 3,38 & 6,68 & 377,26 \\
\hline 04 & 1 & 1 & -1 & 5,80 & 39,88 & 21,69 & 14,35 & 5,72 & 12,56 & 375,43 \\
\hline 05 & -1 & -1 & 1 & 8,1 & 64,83 & 11,54 & 6,74 & 3,17 & 5,62 & 366,14 \\
\hline 06 & 1 & -1 & 1 & 6,6 & 41,53 & 21,03 & 13,64 & 5,69 & 11,51 & 373,00 \\
\hline 07 & -1 & 1 & 1 & 7,4 & 63,64 & 11,41 & 8,32 & 3,29 & 5,94 & 375,08 \\
\hline 08 & 1 & 1 & 1 & 6,8 & 39,20 & 21,02 & 15,82 & 5,67 & 11,49 & 383,26 \\
\hline 09 & 0 & 0 & $-1,68$ & 6,5 & 52,41 & 15,76 & 11,48 & 4,62 & 9,23 & 376,00 \\
\hline 10 & 0 & 0 & 1,68 & 7,4 & 50,77 & 16,73 & 11,75 & 4,51 & 8,84 & 375,75 \\
\hline 11 & 0 & $-1,68$ & 0 & 6,7 & 52,03 & 15,89 & 11,20 & 4,56 & 9,62 & 372,48 \\
\hline 12 & 0 & 1,68 & 0 & 7,9 & 50,24 & 15,47 & 12,56 & 4,32 & 9,51 & 375,88 \\
\hline 13 & $-1,68$ & 0 & 0 & 8,0 & 70,23 & 9,01 & 5,86 & 2,61 & 4,29 & 369,70 \\
\hline 14 & 1,68 & 0 & 0 & 7,0 & 32,29 & 21,22 & 18,84 & 6,60 & 14,05 & 383,60 \\
\hline $15(\mathrm{C})$ & 0 & 0 & 0 & 7,4 & 50,86 & 15,27 & 11,93 & 4,52 & 10,02 & 371,89 \\
\hline $16(\mathrm{C})$ & 0 & 0 & 0 & 7,7 & 51,45 & 15,17 & 11,60 & 4,26 & 9,82 & 370,88 \\
\hline $17(\mathrm{C})$ & 0 & 0 & 0 & 7,6 & 51,38 & 15,28 & 11,49 & 4,54 & 9,71 & 370,05 \\
\hline $18(\mathrm{C})$ & 0 & 0 & 0 & 6,8 & 50,96 & 15,80 & 11,73 & 4,59 & 10,12 & 372,61 \\
\hline
\end{tabular}

$\mathrm{x}_{1}=$ Castanha $(\%) ; \mathrm{x}_{2}=$ Umidade $(\%) ; \mathrm{x}_{3}=$ Temperatura $\left({ }^{\circ} \mathrm{C}\right) ;(\mathrm{C})=$ ponto central; $\mathrm{e} *$ Médias das duplicatas.

Tabela 4. Coeficientes de regressão dos parâmetros do modelo estatístico das variáveis dependentes (composição centesimal = respostas).

\begin{tabular}{|c|c|c|c|c|c|c|c|c|}
\hline \multirow{2}{*}{$\begin{array}{c}\text { Variáveis } \\
\text { independentes }\end{array}$} & \multirow{2}{*}{$\begin{array}{c}\text { Parâmetros } \\
\text { do modêlo }\end{array}$} & \multicolumn{7}{|c|}{ Coeficientes de regressão/respostas } \\
\hline & & $\mathrm{U}$ & $\mathrm{C}$ & $\mathrm{P}$ & $\mathrm{L}$ & $\mathrm{Cz}$ & FAT & kcal \\
\hline Média & $\beta_{0}$ & $7,40^{*}$ & $51,09^{*}$ & $15,34^{*}$ & $11,77^{*}$ & $4,48^{*}$ & $9,92^{*}$ & $371,65^{*}$ \\
\hline (1) Castanha (L) & $\beta_{1}$ & $-0,35^{*}$ & $-11,51^{*}$ & $4,32^{*}$ & $3,39^{*}$ & 1,21 & 2,95 & $1,71^{*}$ \\
\hline Castanha (Q) & $\beta_{11}$ & $-0,06$ & $0,35^{*}$ & 0,08 & $-0,13^{\star *}$ & 0,04 & $-0,28^{*}$ & 0,61 \\
\hline (2) Umidade (L) & $\beta_{2}$ & 0,07 & $-1,10^{*}$ & 0,01 & $1,04^{*}$ & $-0,02$ & 0,01 & $4,95^{\star}$ \\
\hline Umidade (Q) & $\beta_{22}$ & $-0,13$ & $0,31^{*}$ & $0,28^{*}$ & $-0,29^{*}$ & $-0,02$ & $-0,14^{* *}$ & $-0,26$ \\
\hline (3) Temperatura(L) & $\beta_{3}$ & $0,39^{*}$ & $-0,50^{*}$ & $-0,04$ & $0,52^{*}$ & $-0,04$ & $-0,34^{\star}$ & $2,52^{\star}$ \\
\hline Temperatura (Q) & $\beta_{33}$ & $-0,26$ & $0,47^{\star}$ & $0,48^{\star}$ & $-0,39^{*}$ & 0,02 & $-0,33^{*}$ & 0,34 \\
\hline $1 \mathrm{~L} \times 2 \mathrm{~L}$ & $\beta_{12}$ & 0,08 & $-0,09$ & $-0,07$ & $0,25^{*}$ & $-0,05$ & $-0,12$ & $1,58^{\star}$ \\
\hline $1 \mathrm{~L} \times 3 \mathrm{~L}$ & $\beta_{13}$ & $-0,13$ & $-0,27^{*}$ & $-0,03$ & $0,55^{\star}$ & 0,00 & $-0,12$ & $3,75^{\star}$ \\
\hline $2 \mathrm{~L} \times 3 \mathrm{~L}$ & $\beta_{23}$ & 0,01 & $0,62^{*}$ & $-0,14$ & $-0,54^{*}$ & 0,02 & 0,04 & $-2,94^{*}$ \\
\hline $\mathrm{R}^{2}$ & - & 0,67 & 0,99 & 0,96 & 0,91 & 0,99 & 0,99 & 0,62 \\
\hline Erro puro & - & 0,16 & 0,08 & 0,08 & 0,03 & 0,02 & 0,03 & 1,26 \\
\hline
\end{tabular}

$\mathrm{U}=$ umidade (\%); $\mathrm{C}=$ carboidrato (\%); $\mathrm{P}=$ proteína (\%); $\mathrm{L}=$ lipídio (\%); $\mathrm{Cz}=$ cinza (\%); (\%); FAT = fibra alimentar total; kcal = valor calórico; n.s. = Número não significativo em itálico; $\mathrm{R}^{2}=$ coeficiente de determinação explicado pelo modelo; ${ }^{*}$ Variável estatisticamente significativa a um intervalo de confiança de $95 \%$; ${ }^{* *}$ Variável estatisticamente significativa a um intervalo de confiança de $90 \%$. 
A anova do modelo ajustado (Tabela 5) mostrou um $\mathrm{F}_{\mathrm{c}}=7,94 \mathrm{e}$ um $F_{t}(0,95 ; 2: 15)=3,68$ (apenas 2,15 vezes maior que o $\left.F_{t}\right)$.

Segundo Barros Neto, Scarminio e Bruns (1995), para que uma regressão seja não apenas estatisticamente significativa, mas também válida para fins preditivos, o valor da razão $M Q R / M Q_{r}$, ou seja, de $\mathrm{F}_{\mathrm{c}}$, deve ser no mínimo 4 a 5 vezes o valor de $\mathrm{F}_{\mathrm{t}}$, e o $\mathrm{R}^{2}$ deve ser maior ou igual a $60 \%$. Neste caso, a anova (Tabela 5) mostrou o coeficiente de correlação $\mathrm{R}^{2}$ (variação explicada pelo modelo) $=0,51$ e o $\mathrm{F}_{\mathrm{c}}$ muito baixo, sendo o modelo inválido para fins preditivos, não justificando a apresentação de gráficos.

Os coeficientes de regressão do modelo para carboidratos (Tabela 4) mostram que, com exceção da interação castanha X umidade, os demais parâmetros e interações foram significativos $(p \leq 0,05)$. Castanha, umidade e temperatura lineares, com valores de sinais negativos, indicam que se há aumento dos percentuais destas variáveis, o carboidrato diminui, porém a castanha é a variável que mais influencia na redução de carboidratos. As citadas variáveis independentes e a interação umidade e temperatura com valores de sinais positivos significam que a superfície de resposta apresenta o formato com concavidade voltada para cima. Castanha e temperatura lineares com sinal negativo indicam que a elevação destes dois fatores resulta numa redução de carboidrato. A anova modificada (Tabela 6) resultou em $\mathrm{R}^{2}=0,99 ; \mathrm{F}_{\mathrm{c}}=188,13 ; \mathrm{F}_{\mathrm{t}}=3,23$; baixo erro puro e desvio, porém o $F_{c}$ da falta de ajuste $=20,41$ foi maior que o $F_{t}$ mas o modelo é considerado válido para fins preditivos, pois neste caso a $\mathrm{F}_{\text {cfaj }}$ torna-se irrelevante. As Figuras $2 \mathrm{a}, 2 \mathrm{~b}$ e $2 \mathrm{c}$ ilustram as superfícies de respostas e contorno dos efeitos das variáveis de extrusão sobre os carboidratos.

O processo de extrusão pode influenciar a taxa de digestão e absorção do amido através da gelatinização, deixando-o pron- tamente disponível para a degradação com amilase, ou formar o complexo amilose-lipídio (MIRANDA, 1998).

Os resultados dos coeficientes de regressão para proteínas estão apresentados na Tabela 4. Dos parâmetros obtidos, apenas castanha (L) e umidade e temperatura (Q) apresentaram significância $(p \leq 0,05)$. A castanha linear com valor de sinal positivo explica que elevando-se o valor de castanha o percentual de proteínas aumenta. A umidade e a temperatura $(\mathrm{Q})$ com valores positivos mostram uma superfície de resposta direcionada para cima, com uma possível região de máxima.

$\mathrm{Na}$ anova ajustada (Tabela 7), o $\mathrm{R}^{2}=0,97 ; \mathrm{o} \mathrm{F}_{\mathrm{c}}=142,58$; o $\mathrm{F}_{\mathrm{t}}=3,34$; e o erro puro $=0,08$ explicam o modelo válido para fins preditivos. As Figuras 3a, 3b e 3c ilustram as superfícies de respostas dos efeitos das variáveis de extrusão sobre as proteínas nos ensaios experimentais.

Geralmente o processo de extrusão aumenta a digestibilidade das proteínas, especialmente pela inativação de fatores antinutricionais e sua desnaturação (EL-DASH, 1982). Desse modo, as proteínas extrusadas são mais susceptíveis ao ataque de enzimas proteolíticas (ASP; BJORCK, 1989).

Lira Filho (2001) estudou os efeitos de diferentes temperaturas de extrusão $\left(116,130,150,170\right.$ e $\left.184^{\circ} \mathrm{C}\right)$, a porcentagem de umidade $(18,20,23$ e $26 \%)$ e a rotação do parafuso do extrusor $(106,120,140,160$ e $174 \mathrm{rpm})$ sobre o percentual protéico de farinha integral de feijão caupi e concluiu que os resultados dos teores protéicos não variaram entre os tratamentos.

$\mathrm{Na}$ farinha crua de feijão caupi, o teor protéico foi de $23,65 \%$ e em todos os tratamentos das farinhas extrusadas o valor elevou-se para 25,5\%. Miranda (1998), estudando o efeito de diferentes temperaturas de extrusão $(106,120,140,160$ e

Tabela 5. Análise de variância para o modelo ajustado dos resultados de umidade.

\begin{tabular}{lcccccc}
\hline Fonte de variação & Soma quadrática & Graus de liberdade & Média quadrática & $\mathrm{F}_{\text {calculado }}$ & $\mathrm{F}_{\text {tabelado }}$ & $\mathrm{F}_{c} / \mathrm{F}_{\mathrm{t}}$ \\
\hline Regressão & 3,82 & 2 & 1,91 & 7,94 & 3,68 & - \\
Resíduos & 3,61 & 15 & 0,24 & - & - & - \\
Falta de ajuste & 3,12 & 12 & 0,26 & 1,60 & - & -15 \\
Erro puro & 0,49 & 3 & 0,16 & - & - & - \\
Total & 7,42 & 17 & 0,44 & - & - & - \\
$\mathrm{R}^{2}$ & 0,51 & - & - & - & 3,68 & - \\
$\mathrm{F}_{\mathrm{t}}(0,95 ; 2 ; 15)$ & - & - & - & - & 8,74 & - \\
$\mathrm{F}_{\mathrm{t}}(0,95 ; 12 ; 3)$ & - & - & - & - & - \\
\hline
\end{tabular}

Tabela 6. Análise de variância para o modelo ajustado dos resultados de carboidrato.

\begin{tabular}{|c|c|c|c|c|c|c|}
\hline Fonte de variação & Soma quadrática & Graus de liberdade & Média quadrática & $\mathrm{F}_{\text {calculado }}$ & $\mathrm{F}_{\text {tabelado }}$ & $\mathrm{F}_{\mathrm{c}} / \mathrm{F}_{\mathrm{t}}$ \\
\hline Regressão & 1835,35 & 8 & 229,42 & 188,13 & 3,23 & 58,25 \\
\hline Resíduos & 10,98 & 9 & 1,22 & - & - & - \\
\hline Falta de ajuste & 10,71 & 6 & 1,79 & 20,41 & 8,94 & 2,28 \\
\hline Erro puro & 0,26 & 3 & 0,09 & - & - & - \\
\hline Total & 1846,33 & 17 & 108,61 & - & - & - \\
\hline $\mathrm{R}^{2}$ & 0,99 & - & - & - & - & - \\
\hline $\mathrm{F}_{t}(0,95 ; 8 ; 9)$ & - & - & - & - & 3,23 & - \\
\hline$F_{t}(0,95 ; 6 ; 3)$ & - & - & - & - & 8,94 & - \\
\hline
\end{tabular}



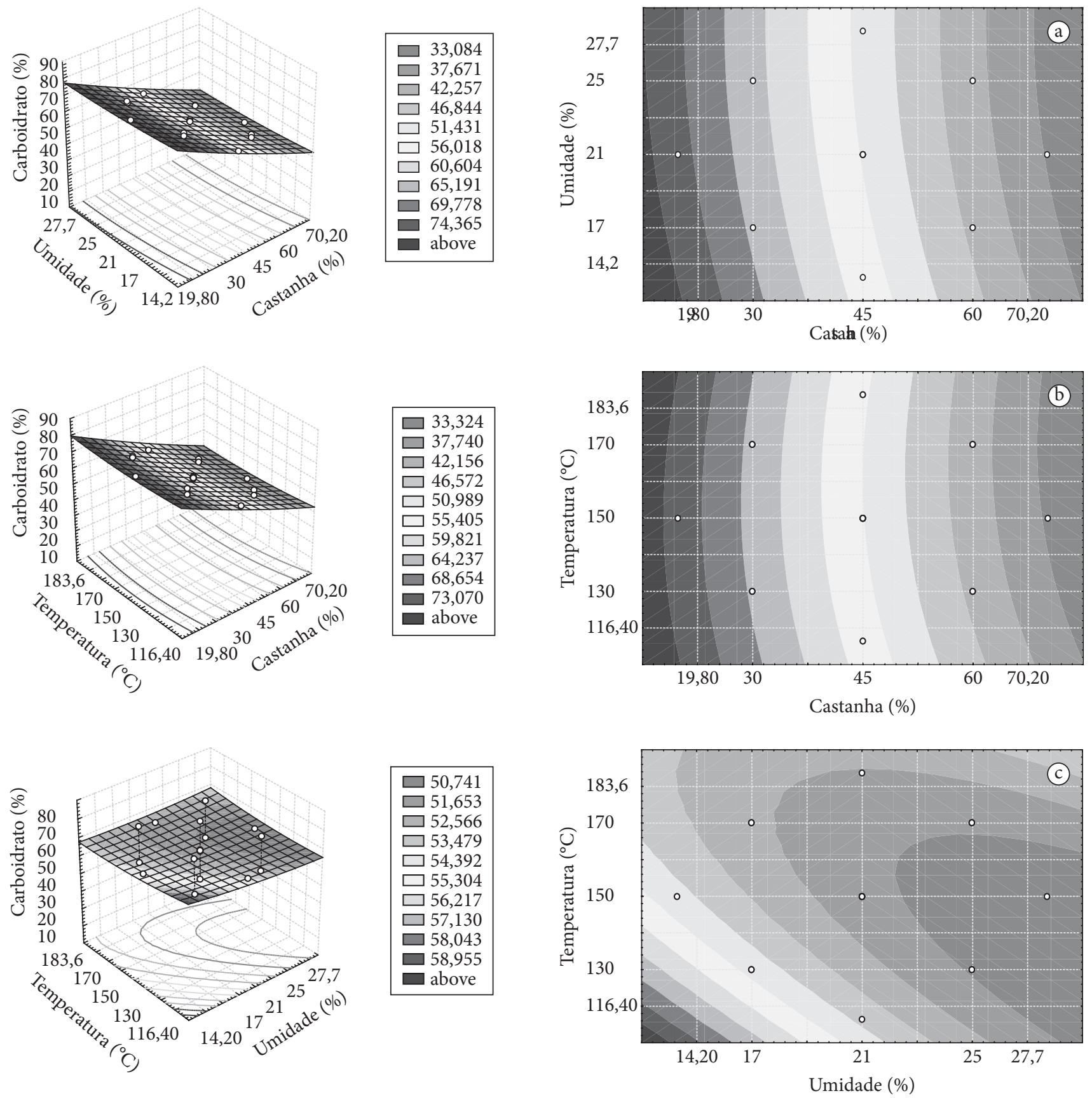

Figura 2. a) Superfície de resposta e contorno mostrando o efeito das variáveis de extrusão sobre os carboidratos, para a temperatura no nível zero $\left(150^{\circ} \mathrm{C}\right)$; b) Superfície de resposta e contorno mostrando o efeito das variáveis de extrusão sobre os carboidratos, para a umidade fixa no nível zero (21\%); e c) Superfície de resposta e contorno mostrando o efeito das variáveis de extrusão sobre os carboidratos, para a castanha fixa no nível zero (45\%).

Tabela 7. Análise de variância para o modelo ajustado dos resultados de proteína.

\begin{tabular}{lcccccc}
\hline Fonte de variação & Soma quadrática & Graus de liberdade & Média quadrática & $\mathrm{F}_{\text {calculado }}$ & $\mathrm{F}_{\text {tabelado }}$ & $\mathrm{F}_{c} / \mathrm{F}_{\mathrm{t}}$ \\
\hline Regressão & 257,96 & 3 & 85,99 & 142,58 & 3,34 & - \\
Resíduos & 8,44 & 14 & 0,60 & - & 9,63 \\
Falta de ajuste & 8,20 & 11 & 0,75 & - & 8,76 & - \\
Erro puro & 0,24 & 3 & 0,08 & - & - & - \\
Total & 266,40 & 17 & 15,67 & - & - & - \\
$\mathrm{R}^{2}$ & 0,97 & - & - & - & 3,34 & - \\
$\mathrm{F}_{\mathrm{t}}(0,95 ; 3 ; 14)$ & - & - & - & - & 8,76 & - \\
$\mathrm{F}_{\mathrm{t}}(0,95 ; 11 ; 3)$ & - & - & - & -
\end{tabular}



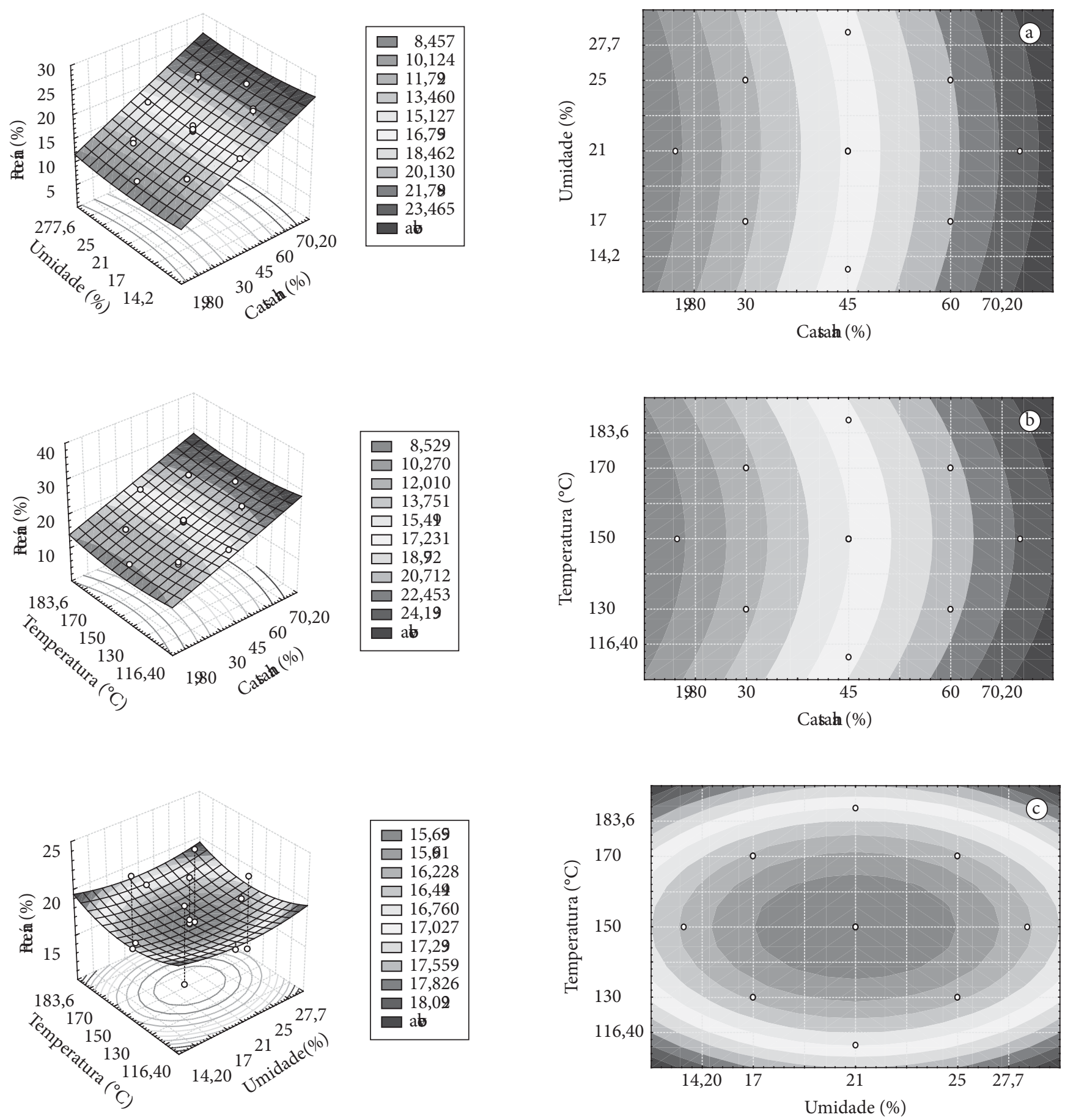

Figura 3. a) Superfície de resposta e contorno mostrando o efeito das variáveis de extrusão sobre as proteínas, para a temperatura fixa no nível zero $\left(150^{\circ} \mathrm{C}\right)$; b) Superfície de resposta e contorno mostrando o efeito das variáveis de extrusão sobre as proteínas, para a umidade fixa no nível zero (21\%); e c) Superfície de resposta e contorno mostrando o efeito das variáveis de extrusão sobre as proteínas, para a castanha fixa no nível zero (45\%).

$174^{\circ} \mathrm{C}$ ) sobre o teor protéico de farinha integral extrusada de trigo germinado, comprovou que o teor protéico diminuiu com o decréscimo da temperatura de extrusão. No entanto, afirma que o motivo para este comportamento é desconhecido.

Nos resultados obtidos para lipídios (Tabela 4) verificase que todos os parâmetros foram significativos a $\mathrm{p} \leq 0,05$, com exceção de castanha (Q) que foi significativo a $\mathrm{p} \leq 0,10$. A castanha foi a variável que mais influenciou nas respostas de lipídios, significando que quanto mais se aumenta o teor de castanha maior é a quantidade de lipídios. A umidade e a temperatura (L) com valores de sinais positivos explicam que a elevação desses fatores implica no aumento de lipídios. Porém, 
Tabela 8. Análise de variância para o modelo completo dos resultados de lipídio.

\begin{tabular}{lcccccc}
\hline Fonte de variação & Soma quadrática & Graus de liberdade & Média quadrática & $\mathrm{F}_{\text {calculado }}$ & $\mathrm{F}_{\text {tabelado }}$ & $\mathrm{F}_{\mathrm{c}} / \mathrm{F}_{\mathrm{t}}$ \\
\hline Regressão & 182,43 & 9 & 20,27 & 9,68 & - & - \\
Resíduos & 16,76 & 8 & 2,09 & - & - & - \\
Falta de ajuste & 16,65 & 5 & 3,33 & 93,14 & - & - \\
Erro puro & 0,11 & 3 & 0,04 & - & - & - \\
Total & 199,19 & 17 & 11,72 & - & - & - \\
$\mathrm{R}^{2}$ & 0,92 & - & - & - & 3,39 & - \\
$\mathrm{F}_{\mathrm{t}}(0,95 ; 9 ; 8)$ & - & - & - & - & 9,01 & - \\
$\mathrm{F}_{\mathrm{t}}(0,95 ; 5 ; 3)$ & - & - & & - & - \\
\hline
\end{tabular}
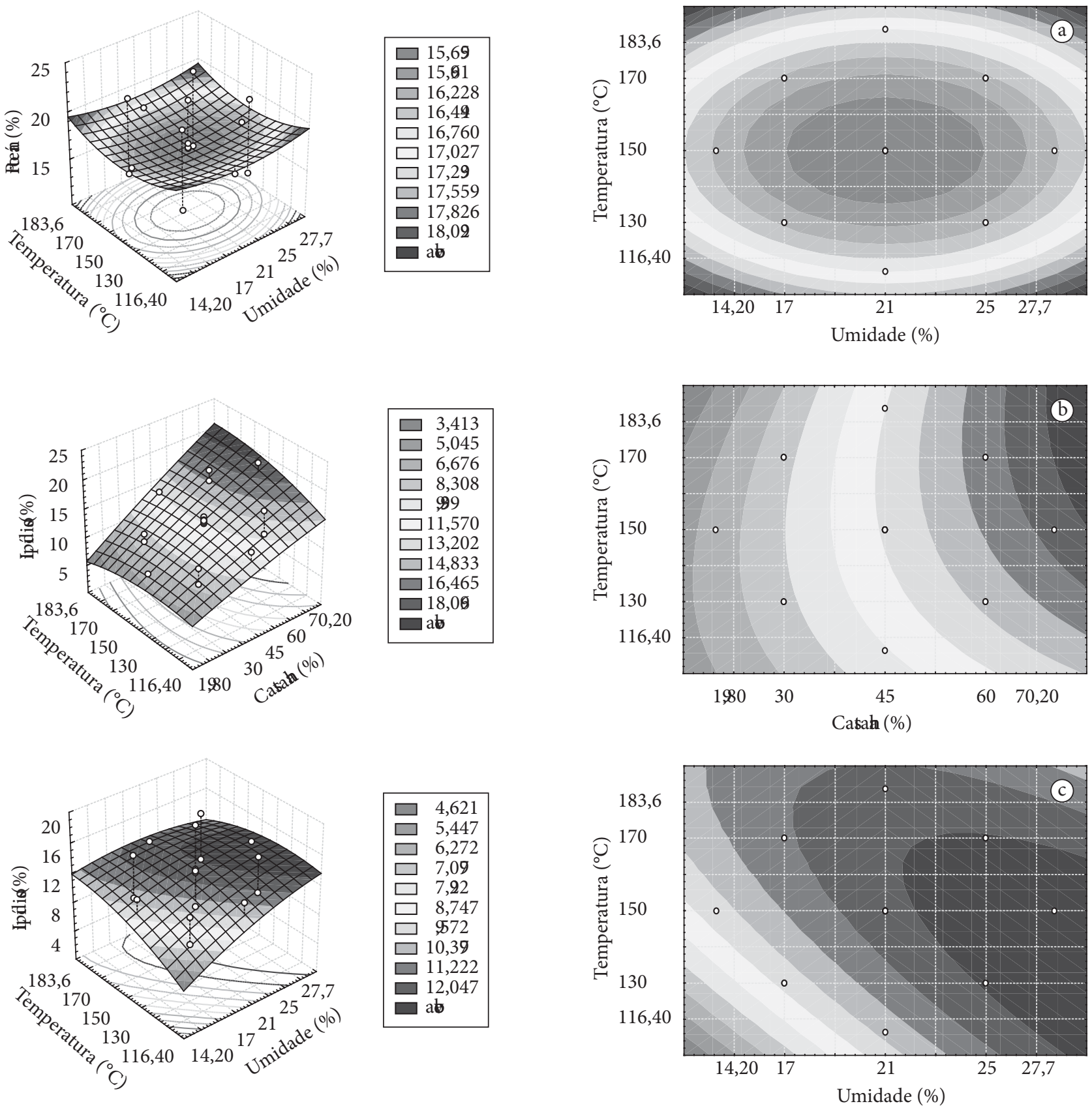

Figura 4. a) Superfície de resposta e contorno mostrando o efeito das variáveis de extrusão sobre os lipídios, para a temperatura fixa no nível zero $\left(150^{\circ} \mathrm{C}\right)$; b) Superfície de resposta e contorno mostrando o efeito das variáveis de extrusão sobre os lipídios, para a umidade fixa no nível zero (21\%); e c) Superfície de resposta e contorno mostrando o efeito das variáveis de extrusão sobre os lipídios, para a castanha fixa no nível zero (45\%). 
a castanha, a umidade e a temperatura $(\mathrm{Q})$ indicam superfície com curvatura, já os valores com sinais negativos mostram que há uma região de máxima, com a concavidade da superfície voltada para baixo.

A análise de variância completa (Tabela 8) apresentou $R^{2}=0,92 ; F_{c}=9,68 ; F_{t}=3,39 ;$ e erro puro $=0,04$, portanto, um modelo viável mesmo com um alto valor para $\mathrm{F}_{\text {cfaj }}=93,14$ contra um $F_{\text {tfai }}=9,01$. As Figuras 4a, 4b e 4c ilustram as superfícies de respostas e contorno das variáveis de extrusão sobre os percentuais de lipídios dos extrusados.

Os resultados de coeficiente de regressão e dos parâmetros do modelo para cinzas (Tabela 4) mostram que apenas castanha linear com valor positivo apresentou significância a 95\% de probabilidade. Isto indica que elevando o teor de castanha nos extrusados o teor de cinza também aumenta.

Miranda (1998), pesquisando a quantidade de cinzas em farinhas integrais extrusadas de trigo germinado, observou que as diferentes temperaturas de extrusão não alteraram os percentuais de cinzas, conclusão que corrobora com o que foi verificado neste trabalho.

A ANOVA modificada (Tabela 9) resultou o $\mathrm{R}^{2}$ (coeficiente de correlação) da variação explicada pelo modelo igual a 0,99 ; $\mathrm{F}_{\mathrm{c}}=1720,36 ; \mathrm{F}_{\mathrm{t}}=4,49 \mathrm{e} \mathrm{F}_{\text {cfaj }}=0,42$, contra $\mathrm{F}_{\text {tfaj }}=8,37$ e erro puro muito baixo para cinzas. Apesar de todos os indicadores apontarem para um modelo preditivo, apenas uma variável (castanha linear) foi significativa, impossibilitando assim gerar um gráfico de superfície de resposta.

Os resultados dos coeficientes de regressão e parâmetros do modelo estatístico encontrados para kcal.100 $\mathrm{g}^{-1}$ estão citados na Tabela 4 . Os extrusados apresentaram em média $371,65 \mathrm{kcal} .100 \mathrm{~g}^{-1}$, podendo ser empregados na alimentação como um produto protéico-calórico. Gutkoski (1997) e Miranda (1998), estudando a quantidade de energia metabolizável em kcal. $100 \mathrm{~g}^{-1}$ de aveia e trigo integral extrusados, encontraram em média $371,03 \mathrm{kcal} 100 \mathrm{~g}^{-1}$ na cariopse de aveia, 362,23 kcal.100 g $\mathrm{g}^{-1}$ na fração aveia moída e $354,59 \mathrm{kcal} .100 \mathrm{~g}^{-1}$ no trigo. Assim, o valor médio em kcal.100 g ${ }^{-1}$ obtido neste trabalho $(371,65)$ está condizente aos valores dos cereais integrais citados.

$\mathrm{Na}$ Tabela 4 observa-se que castanha, umidade e temperatura lineares, apresentaram-se significativos ( $p \leq 0,05)$, com valores positivos, indicando que elevando-se estes fatores, os resultados em kcal também aumentam. As interações castanha $\mathrm{X}$ umidade e castanha $x$ temperatura mostram uma elevação da resposta (kcal), pois os valores são positivos, porém a interação umidade $x$ temperatura com valor de sinal negativo mostrou que elevando-se estas duas variáveis, ocorre uma redução em calorias.

A anova modificada (Tabela 10) evidenciou $\mathrm{R}^{2}=0,62$, um $\mathrm{F}_{\mathrm{c}}$ baixo, uma relevante falta de ajuste e significante erro puro, assinalando um modelo inválido que não deve ser utilizado para fins preditivos, não justificando apresentar a superfície de resposta.

As equações codificadas dos modelos de regressão completos ou ajustados, preditos para as respostas de carboidratos, proteínas, lipídios e kcal estão apresentadas abaixo (Equações 3, 4, 5, 6):

Carboidratos $=51,09-11,51 \mathrm{C}+0,35 \mathrm{C}^{2}-1,10 \mathrm{U}+0,31 \mathrm{U}^{2}-$ $0,50 \mathrm{~T}+0,47 \mathrm{~T}^{2}-0,27 \mathrm{CT}+0,62 \mathrm{UT}$

Proteínas $=15,34+4,32 \mathrm{C}+0,28 \mathrm{U}^{2}+0,48 \mathrm{~T}^{2}$

Lipídios $=11,77=3,39 \mathrm{C}-0,13 \mathrm{C}^{2}+1,04 \mathrm{U}-0,29 \mathrm{U}^{2}+$ $0,52 \mathrm{~T}^{2}-0,39 \mathrm{~T}^{2}+0,25 \mathrm{CU}-0,54 \mathrm{UT}$

$\mathrm{kcal}=371,65+1,71 \mathrm{C}+4,95 \mathrm{U}^{2}+2,52 \mathrm{~T}+1,58 \mathrm{CU}+3,75 \mathrm{CT}-2,94 \mathrm{UT}$

Tabela 9. Análise de variância para o modelo ajustado dos resultados de cinza.

\begin{tabular}{|c|c|c|c|c|c|c|}
\hline Fonte de variação & Soma quadrática & Graus de liberdade & Média quadrática & $\mathrm{F}_{\text {calculado }}$ & $\mathrm{F}_{\text {tabelado }}$ & $\mathrm{F}_{\mathrm{c}} / \mathrm{F}_{\mathrm{t}}$ \\
\hline Regressão & 20,01 & 1 & 20,01 & 1720,36 & 4,49 & 382,81 \\
\hline Resíduos & 0,19 & 16 & 0,01 & - & - & - \\
\hline Falta de ajuste & 0,12 & 13 & 0,01 & 0,42 & 8,73 & 0,04 \\
\hline Erro puro & 0,07 & 3 & 0,02 & - & - & - \\
\hline Total & 20,19 & 17 & 1,19 & - & - & - \\
\hline $\mathrm{R}^{2}$ & 0,99 & - & - & - & - & - \\
\hline$F_{t}(0,95 ; 13 ; 3)$ & - & - & - & - & 8,73 & - \\
\hline
\end{tabular}

Tabela 10. Análise de variância para o modelo ajustado dos resultados de kcal.100 g $\mathrm{g}^{-1}$.

\begin{tabular}{lccccc}
\hline Fonte de variação & Soma quadrática & Graus de liberdade & Média quadrática & $\mathrm{F}_{\text {calculado }}$ & $\mathrm{F}_{\mathrm{c}} / \mathrm{F}_{\mathrm{t}}$ \\
\hline Regressãolado & 663,20 & 6 & 110,53 & 3,02 & - \\
Resíduos & 402,36 & 11 & 36,58 & - & - \\
Falta de ajuste & 398,57 & 8 & 49,82 & 39,44 & - \\
Erro puro & 3,79 & 3 & 1,26 & - & - \\
Total & 1065,56 & 17 & 62,68 & - & - \\
$\mathrm{R}^{2}$ & 0,62 & - & - & - & - \\
$\mathrm{F}_{\mathrm{t}}(0,95 ; 6 ; 11)$ & - & - & - & - & - \\
$\mathrm{F}_{\mathrm{t}}(0,95 ; 8 ; 3)$ & - & - & - & -
\end{tabular}




\section{Conclusões}

A castanha do Brasil é a variável independente que apresenta mais influência no aumento dos percentuais de proteínas, cinzas, fibras e lipídios das misturas extrusadas.

Os extrusados das formulações com menores percentuais de castanha e maiores de mandioca apresentam-se mais expandidos e de coloração clara, já os extrusados com maiores teores de castanha e menores de mandioca não se expandem e têm a coloração acinzentada.

O valor energético médio em energia metabolizável dos produtos extrusados é elevado e os produtos considerados como alimentos protéico-energéticos.

A tecnologia de extrusão é uma alternativa tecnológica viável para processar misturas de castanha do Brasil desengordurada com farinha de mandioca e obter alimento prático e pronto para consumo.

Justifica-se o aproveitamento de castanha do Brasil desengordurada com farinha de mandioca pela tecnologia de extrusão, por disponibilizar ao mercado um produto alimentício alternativo rico em proteína vegetal, carboidratos, lipídios, fibras e selênio, contribuindo para a diversificação de produtos alimentícios desse grupo, similares aos cereais matinais existentes no mercado.

\section{Agradecimentos}

Os autores agradecem à Universidade Federal do AcreUFAC, à Universidade Estadual de Campinas-UNICAMP, à Fundação de Amparo à Pesquisa do Estado de São PauloFAPESP e ao Conselho Nacional de Desenvolvimento Científico e Tecnológico-CNPq, pela oportunidade, pelo auxílio financeiro ao projeto e pela bolsa concedidos.

\section{Referências bibliográficas}

AOAC - American Association of Cereal Chemists. Approved methods of the American Association of Cereal Chemists. 9. ed. Saint Paul: AACC, 1995. v. 2.

ANDERSON, L. A. et al. Nutrição. Rio de Janeiro: Guanabara, 1988. cap. 10 , p. $179-187$.

AINSWORTH, P. et al. Influence of extrusion variables on the protein in vitro digestibility and protein solubility of extruded soy tarhana. Journal of the Science of Food and Agriculture, London, v. 79, n. 5, p. 675-678, 1999.

ALONSO, R.; AGUIRRE, A.; MARZO, F. Effects of extrusion and traditional processing methods on antinutrients and in vitro digestibility of protein and starch in faba and kidney beans. Food Chemistry, Oxford, v. 68, n. 2, p. 159-165, 2000.

ARTZ, W. E.; WARREN, C.; VILLOTA, R. Twin screw extrusion modification of a corn fiber and corn starch extrudes blend. Journal of Food Science, Chicago, v. 55, n. 3, p. 746-754, 1990.

ASP, N. G.; BJORCK, I. Nutritional properties of extruded. In: MERCIER, C.; LINKO, P.; HARPER, J. M. (Eds.). Extrusion cooking. St. Paul: AACC, 1989. p. 399-434.

BARROS NETO, B. DE; SCARMINIO, I. S.; BRUNS, R. E. Planejamento e otimização de experimentos. 2. ed. Campinas: Ed. UNICAMP, 1995. 299 p.
CAMIRE, M. E.; CAMIRE, A.; KRUMHAR, K. Chemical and nutritional changes in foods during extrusion. Critical Reviews in Food Science and Nutrition, Boca Raton, v. 29, n. 1, p. 35-57, 1990.

UFRGS - UNIVERSIDADE FEDERAL DO RIO GRANDE DO SUL. Cereais. Disponível em: <http://www.ufrgs.br/Alimentus/feira/ prcerea/extrusad/consider.htm>. Acesso em: 03 dez. 2006.

CHANG, Y. K. et al. Influence of extrusion conditions on cassava starch and soybean protein concentrate blends. Acta Alimentaria, Budapest, v. 30, n. 2, p. 189-203, 2001.

CHEN, J. et al. Effects of extrusion conditions on sensory properties of corn meal extrudates. Journal of Food Science, Chicago, v. 56, n. 1, p. 84-89, 1991.

CHUNHIENG, T. et al. Study of selenium in the protein fractions of the Brazil nut, Bertholletia excelsa. Journal Agricultural and Food Chemistry, Canada, v. 52, n. 13, p. 4318-4322, 2004.

COOPERATIVA AGRO-EXTRATIVISTA DE XAPURI-AC. Castanha do Brasil (Bertlholletia excelsa, H. B.K.). Rio Branco: [s.n.], 2002.

COZZOLINO, S. M. Novas recomendações de nutrientes interpretação e utilização. In: USOS E APLICAÇÕES DAS "DIETARY REFERENCE INTAKE”. DRIS. São Paulo: ILSI/SBAN, 2001.

EL-DASH, A. A. Termoplastic extrusion of food, theory and techniques. Campinas: UNICAMP, 1982. $81 \mathrm{p}$.

. Utilização da mandioca na alimentação humana e em outros produtos industrializados. Informe Agropecuário, Rio de Janeiro: Embrapa, p. 74-82, 1987.

GONZAGA, I. Avaliação nutricional relativa ao selênio em crianças com dieta enriquecida de castanha-do-brasil (Bertholletia excelsa, H. B. K.). São Paulo: USP, 2002.

GRIZOTTO, R. K. Mandioca "Chips" Uma tecnologia para o aproveitamento da mandioca (Manihot esculenta Crantz). Campinas, 2000, $130 \mathrm{f}$. Tese (Doutorado em Tecnologia de Alimentos) - Faculdade de Engenharia de Alimentos, Universidade Estadual de Campinas.

GUTKOSKI, L. C. Caracterização tecnológica de frações de moagem de aveia e efeito de umidade e temperatura de extrusão na sua estabilidade. Campinas, 1997, $241 \mathrm{f}$. Tese (Doutorado em Tecnologia de Alimentos) - Faculdade de Engenharia de Alimentos, Universidade Estadual de Campinas.

HARPER, J. M. Extrusion of Food. CRC Press: Boca Raton, 1981, v. $2,174 \mathrm{p}$.

HOLBEN, D. H.; SMITH, A. M. The diverse role of selenium within selenoprotein: a review. Journal of the American Dietetic Association, Philadelphia, v. 99, n. 7, p. 839-843, 1999.

ICTA - Instituto de Ciência e Tecnologia de Alimentos da UFRGS, Universidade Federal do Rio Grande do Sul. Produtos Alimentícios Vegetais: Cereal Matinal. Disponível em: <http://www.ufrgs.br/ Alimentus/feira/afeira.htm>. Acesso em: 24 mar. 2006.

LIRA FILHO, J. F. de. Efeitos da extrusão termoplástica sobre as propriedades tecnológicas e nutritivas das proteínas da farinha integral do feijão caupi (Vigna unguilata (L Walp)). Campinas, 2001. 148 f. Tese (Doutorado em Tecnologia de Alimentos), Faculdade de Engenharia de Alimentos, Universidade Estadual de Campinas.

MIRANDA, M. Z. de. Efeito do tempo de germinação do trigo e das variáveis de extrusão na qualidade tecnológica e nutricional de farinha integral. Campinas, 1998. 216 f. Tese (Doutorado em Tecnologia de Alimentos) - Faculdade de Engenharia de Alimentos, Universidade Estadual de Campinas - UNICAMP.

PACHECO, A. M.; SCUSSEL, V. M. Castanha-do-Brasil: da floresta tropical ao consumidor. Florianópolis: Editorgraf, 2006. 176 p. 
SOARES JÚNIOR, M. S. Propriedades funcionais de extrusados de amido de mandioca (Manihot esculenta Crantz) com monoglicerídio. Londrina, 1995. 120 f. Dissertação (Mestrado em Ciência de Alimentos), Universidade Estadual de Londrina.

SOUZA, M. L. de. Processamento de cereais matinais extrusados de castanha-do-brasil com mandioca. Campinas. 2003. $191 \mathrm{f}$. Tese (Doutorado em Tecnologia de Alimentos) - Faculdade de Engenharia de Alimentos, Universidade Estadual de Campinas, 2003.
SOUZA, M. L. de; MENEZES, H. C. Processamento de amêndoa e torta de castanha -do- Brasil e farinha de mandioca: parâmetros de qualidade. Ciência e Tecnologia de Alimentos, Campinas, v. 24, n. 1, p. 120-128, 2004.

STATISTICA FOR WINDOWS - Versão 5.0. Copyright ${ }^{\oplus}$ StatSoft, Inc., Tulsa, USA, 1995.

YAYLAYAN, V. A.; FICHTALI, J.; VAN DE VOORT, F. R. Production of Maillard reaction flavour precursors by extrusion processing. Food Research International, Ottawa, v. 25, n. 3, p. 175-180, 1992. 